\title{
Hair Part
}

National Cancer Institute

\section{Source}

National Cancer Institute. Hair Part. NCI Thesaurus. Code C38465.

Any component of the filamentous outgrowth of the epidermis. 